\begin{tabular}{|c|c|c|}
\hline UFC & 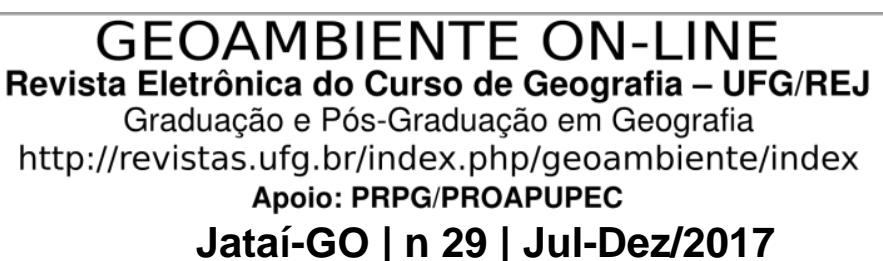 & $\begin{array}{l}\text { @GEO } \\
\text { ISSAMBIENTE } \\
\text { ISSN } 1679-9860\end{array}$ \\
\hline
\end{tabular}

\title{
DESTINAÇÃO DE EFLUENTES SANITÁRIOS NA ÁREA RURAL DO MUNICÍPIO DE CAÇADOR, SANTA CATARINA, BRASIL
}

\author{
Roger Francisco Ferreira de Campos ${ }^{1}$, Tiago Borga ${ }^{2}$, Osni Ribeiro Mello ${ }^{3}$
}

(1 - Universidade Alto Vale do Rio do Peixe, Professor do curso de Engenharia Ambiental e Sanitária, roger@uniarp.edu.br. 2 - Universidade Alto Vale do Rio do Peixe, Professor e Coordenador do curso de Engenharia Ambiental e Sanitária, tiagoborga@gmail.com. 3 Universidade Alto Vale do Rio do Peixe, Engenheiro Civil, osniribeiromello@gmail.com)

RESUMO: Atualmente vinte por cento da população brasileira reside em áreas rurais, uma quantidade expressiva de pessoas que geram grande volume de resíduos sólidos e líquidos, necessitando de um olhar ambiental por parte da comunidade e principalmente pelos órgãos públicos ambientais. Portanto, o presente trabalho tem como objetivo realizar um levantamento descritivo sobre o atual cenário do esgotamento sanitário da área rural do município de Caçador/SC, com um levantamento qualitativo da atual realidade da destinação e tratamento dos efluentes sanitários do município. Com o estudo, pode-se concluir que as áreas rurais do município necessitam de um acompanhamento pelos órgãos ambientais do município, visto que $49.899 \%$ da população possuem poço negro (sumidouro), $44.064 \%$ o sistema de fossa e filtro, e $1.609 \%$ não possuem nenhum tipo de tratamento, causando impactos ambientais no solo devido à falta de tratamento. Assim, o presente estudo visa mostrar para a sociedade atual a presente realidade do município de Caçador, com a perspectiva de buscar alternativas sustentáveis para esses empecilhos ambientais. Conclui-se que o município necessita de um melhor acompanhamento sobre o esgotamento sanitário na área rural.

Palavras chave: Saneamento rural. Esgotamento sanitário. Meio ambiente.

\section{DESTINATION OF SANITARY EFLUENTES IN THE RURAL AREA OF THE MUNICIPALITY OF CAÇADOR, SANTA CATARINA, BRAZIL}

ABSTRACT: Currently twenty percent of the Brazilian population lives in rural areas, an expressive amount of people that generate a large volume of solid and liquid waste, requiring an environmental view by the community and mainly by public environmental agencies.

Artigo recebido para publicação em 29 de Janeiro de 2017

Artigo aprovado para publicação em 20 de Dezembro de 2017 
Therefore, the present work aims to carry out a descriptive survey on the current scenario of sanitary sewage in the rural area of the municipality of Caçador/SC, with a qualitative survey of the current reality of the destination and treatment of sanitary effluents in the municipality. With the study, it can be concluded that the rural areas of the municipality need to be monitored by the municipality's environmental agencies, since $49.899 \%$ of the population have a black well (sink), $44.064 \%$ have a fossa and filter system, and $1.609 \%$ do not No treatment or even home, causing environmental impact on the ground due to lack of treatment. Thus, the present study aims to show current society the present reality of the municipality of Caçador, with the perspective of seeking sustainable alternatives to these environmental obstacles. It is concluded that the municipality needs a better monitoring of the sanitary sewage in the rural area.

Keywords: Rural sanitation. Sanitary sewage. Environment.

\section{DESTINO DE LOS EFLUENTES SANITARIOS EN EL ENTORNO RURAL DEL MUNICIPIO CAÇADOR, SANTA CATARINA, BRAZIL}

RESUMEN: Actualmente el veinte por ciento de la población vive en zonas rurales, una cantidad importante de personas que generan grandes volúmenes de residuos y desechos, lo que requiere un aspecto medioambiental de la comunidad y en especial de las organizaciones públicas. Por lo tanto, este estudio tiene como objetivo llevar a cabo un estudio descriptivo de la situación actual del saneamiento en las zonas rurales del municipio de Caçador/SC, con una encuesta cualitativa de la realidad actual del destino y el tratamiento de las aguas residuales sanitarias del municipio. Con el estudio, podemos concluir que las áreas rurales del municipio requieren la supervisión de las autoridades ambientales del municipio, ya que el 49.899\% de la población tiene también negro (sumidero), el 44.064\% del depósito y el sistema de filtro y el $1.609 \%$ no tienen cualquier tipo de tratamiento o incluso en casa, el suelo causando impacto ambiental debido a la falta de tratamiento. Por lo tanto, este estudio tiene como objetivo mostrar a la sociedad actual esta realidad municipio Caçador, con la perspectiva de la búsqueda de alternativas sostenibles a estos obstáculos ambientales.

Palabras chave: Saneamiento rural. Políticas públicas. Medio ambiente.

\section{Introdução}




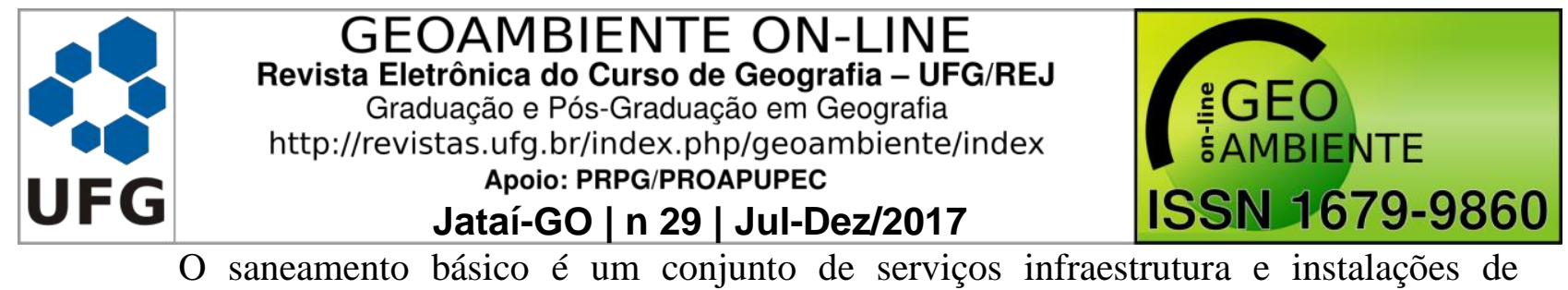

abastecimento de água, esgotamento sanitário, limpeza urbana e manejo de resíduos sólidos e drenagem de águas pluviais urbanas (BRAGA et al., 2005). Dentre esses conjuntos a falta de serviços de esgotamento sanitário traz várias consequências negativas ao meio ambiente quanto a nível urbano e rural, quando não possui um tratamento adequado (LEONETI; PRADO; OLIVEIRA, 2011).

Segundo Rizi-Junior (2014) em uma análise da atual legislação relacionada ao saneamento básico evidencia que o esgotamento sanitário é essencial para a qualidade de vida, visto que à sua falta ocasiona poluição dos recursos hídricos, prejudica a saúde da população e interage diretamente com os ecossistemas. No entanto, investimentos para com o saneamento com ênfase em esgotamento sanitário devem ser desenvolvidos para atender alguns requisitos técnicos que visem à sustentabilidade, preservando e conservando o meio ambiente, mas principalmente a qualidade dos recursos hídricos (LEONETI; PRADO; OLIVEIRA, 2011).

Dados da Pesquisa Nacional por Amostra de Domicílios - PNAD (2012) apontam que apenas $57,1 \%$ dos domicílios brasileiros possuem coleta de esgoto ligada à rede geral e que outros $20,7 \%$ são atendidos por fossa séptica e filtro anaeróbio. No entanto, 22,3\% dos domicílios possuem soluções inadequadas, onde $16,6 \%$ são atendidos por fossas rudimentares, $3,1 \%$ por outras soluções e 2,6\% não possuem nenhum tipo de esgotamento sanitário. O quadro piora quando analisados apenas os domicílios localizados em áreas rurais. Dados da PNAD (2015) revelam que apenas 5,2\% dos domicílios possuem coleta de esgoto ligada à rede geral e 28,3\% fossa sépticas, ligados ou não a uma rede coletora. Fossas rudimentares são adotadas por 45,3\%, outras soluções (fossas rudimentares, valas, despejo em cursos d'água) são adotadas por 7\% dos domicílios e 13,6\% dos domicílios não dispõem de nenhuma solução.

Segundo o IBGE (2012), em um estudo realizado em 2009, dispõem que no Brasil apenas $25 \%$ da população que reside em área rural possui acesso a rede coletora ou tratamento de esgoto doméstico. Porém, a mesma população possui a disponibilidade $84 \%$ de água tratada, essa questão esta relacionada com o processo de gestão dos resíduos e saneamento na área rural, onde possui uma demanda com qualidade, entretanto o tratamento não é adequado (UNICEF, 2016).

Os resíduos líquidos gerados neste processo trazem prejuízos imensos ao meio ambiente, a sociedade e a economia, como a poluição do ar, contaminação do solo 


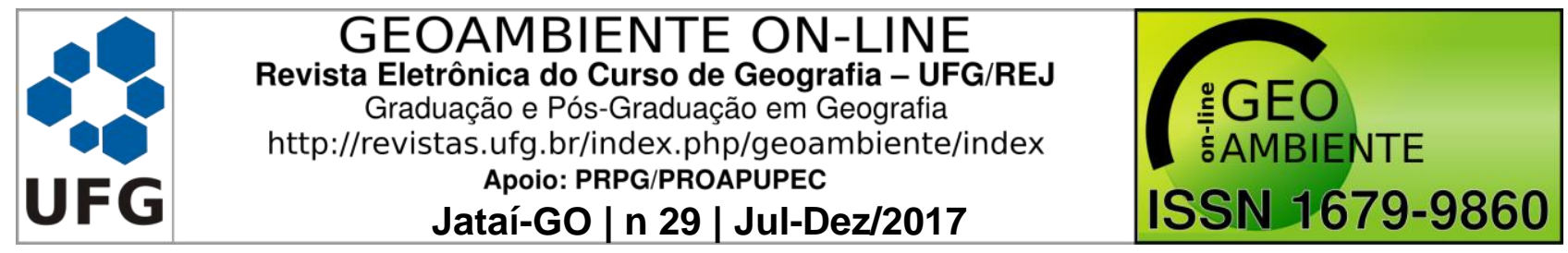

(CALIJURI; CUNHA, 2013), contaminação do lençol e corpos hídricos (SILVA; ALVES; PORTILHO, 2016), e ainda podem trazer riscos à saúde humana e de outros seres vivos, além de acionar a proliferação de insetos e outros agentes vetores de doenças (CALIJURI; CUNHA, 2013). Segundo Novick e Campos (2016) a falta de saneamento básico acaba interferindo na qualidade da água, logo ações de educação ambiental e divulgação de análises deve ser desenvolvidas para uma recuperação dos recursos hídricos.

Segundo Costa e Guilhoto (2014) um dos mecanismos para tratamento do esgotamento doméstico rural é a utilização de métodos de fossas sépticas biodigestoras, que promove a geração de empregos, evita mortes, infecções por diarréia e diminui a poluição dos corpos d'água. O sistema de biodigestão possui a finalidade de reciclar os dejetos e promover a vedação hermética, o que impede a proliferação de vetores de doenças. Segundo Lima et al., (2012) o sistema de biodigestão possibilita a geração de adubo orgânico substituindo os adubos comerciais. Para Freisleben, Grisa e Candiotto (2010) os sistemas de evapotranspiração também são eficientes em áreas rurais para a diminuição da poluição hídrica.

As inovações no sistema descentralizado de águas residuais podem alterar positivamente as formas de gestão dos recursos hídricos. Podendo projetar a recuperação parcialmente da água e nutrientes de forma sustentável, visto que o aumento drasticamente da escassez de água, onde a tecnologia de reuso eficiente da água deve ser almejada como prioridade pelos órgãos governamentais (OTTERPOHL; BRAUN; OLDENBURG, 2002).

A destinação correta do esgotamento sanitário doméstico, tanto nas áreas urbanas quanto nas áreas rurais, ainda é um problema brasileiro. Por isso, da necessidade de estudar como se desenvolve este processo nas propriedades rurais de Caçador (SC), de forma a poder sugerir soluções mais baratas, eficientes e adequadas às particularidades da região. Dentre as dimensões do problema esse trabalho busca diagnosticar o cenário do esgotamento sanitário na área rural do município de Caçador - Santa Catarina, desenvolvendo uma análise descritiva e qualitativa da destinação final dos efluentes sanitários na área rural do município.

\section{Material e Métodos}

O município do estudo está localizado no Meio Oeste do estado de Santa Catarina, nas coordenadas $26^{\circ} 46^{\prime} 30^{\prime \prime} \mathrm{S}$ e $51^{\circ} 0^{\prime} 54^{\prime \prime} \mathrm{W}$, a 920 metros de altitude, com clima subtropical úmido e fuso horário UTC 3 (Figura 1.) Caçador possui área de $981,901 \mathrm{~km}^{2}$, população de 75.812 habitantes (IBGE, 2014) com densidade demográfica de 77,21 hab./km², sendo que 


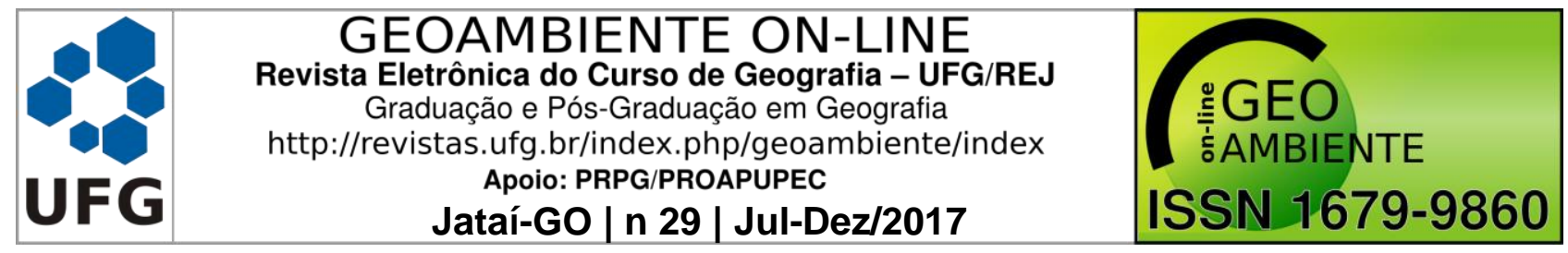

6.304 residem na área rural, representando 8,91\% e 64.431 na área urbana com 91,09\% em domicílios (IBGE, 2011).

Figura 1. Mapa de localização da área de estudo.

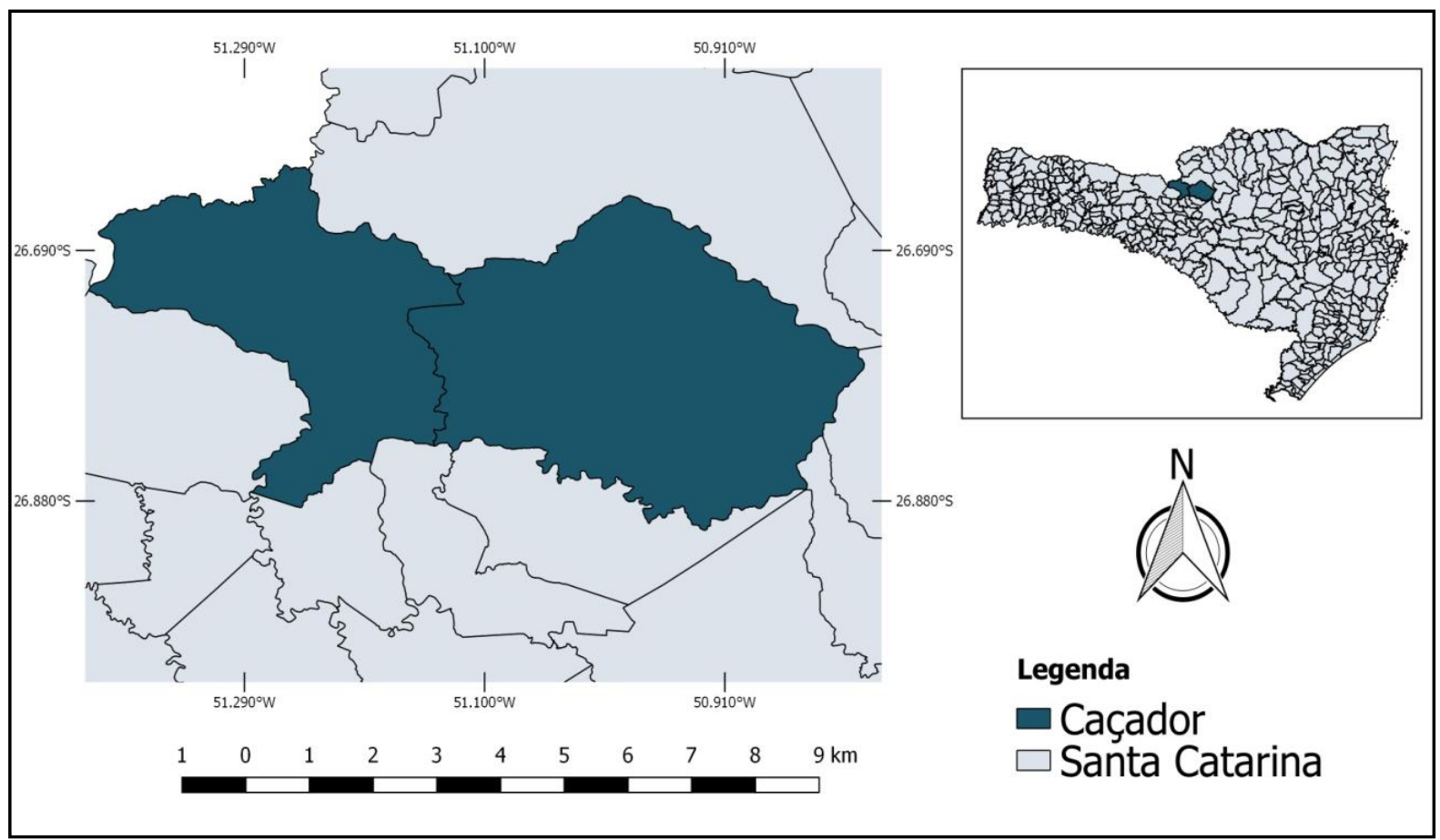

Organização: Autores (2017).

O presente trabalho descritivo realizou um estudo bibliográfico e documental de fontes primárias sobre as questões relacionadas à destinação do esgoto doméstico no meio rural do município de Caçador/SC, obtendo uma abordagem quantitativa e qualitativa com o objetivo de demonstrar o diagnóstico do destino de esgotamento sanitário na área rural do município, buscando conhecer a realidade da comunidade rural do município, através da perspectiva de implementar políticas públicas de saneamento que beneficie a população e ao meio ambiente de Caçador.

\section{Resultados e Discussões}

Com a perspectiva de implantar o Plano Diretor de Rural foi desenvolvido um estudo sobre a análise de destinação do esgoto sanitário na área rural do município de Caçador em conjunto com a Secretaria Municipal de Agricultura de Caçador, o qual busca apresentar as diretrizes para diminuição dos impactos ambientais relacionados com o esgotamento em área 


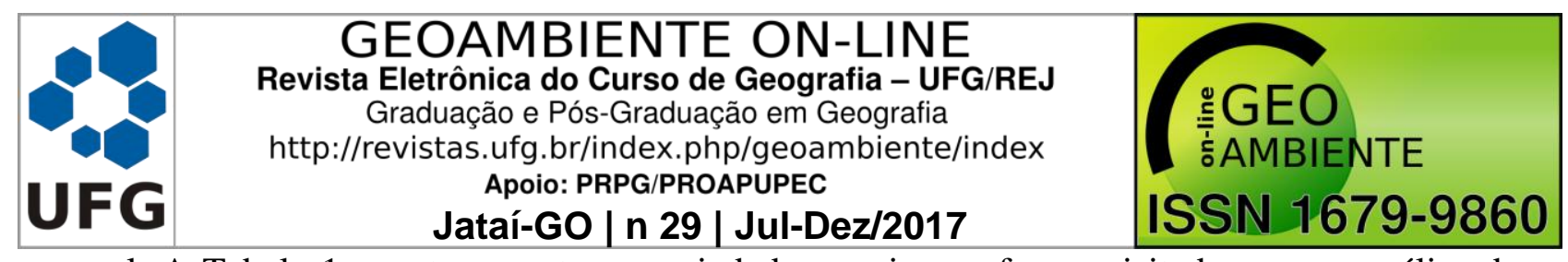

rural. A Tabela 1. mostra quantas propriedades rurais que foram visitadas para a análise da destinação do esgotamento sanitário, atingiu-se 3.855 pessoas na área rural do município, compondo $60 \%$ dos moradores da área rural.

Tabela1. Locais, propriedades e número de entrevistados.

\begin{tabular}{|c|c|c|}
\hline $\begin{array}{l}\text { Ordem das comunidades por números de } \\
\text { estabelecimento }\end{array}$ & $\begin{array}{c}\text { Número de } \\
\text { residências } \\
\text { entrevistadas }\end{array}$ & $\begin{array}{l}\text { Número de } \\
\text { moradores }\end{array}$ \\
\hline Assentamento & 114 & 468 \\
\hline Rio Bugre & 112 & 396 \\
\hline Cará & 85 & 319 \\
\hline Cerro Branco & 71 & 278 \\
\hline SC 451 (até km 18 e Km 26 ao 48) & 68 & 203 \\
\hline São Francisco & 51 & 193 \\
\hline São Paulo & 46 & 179 \\
\hline Caixa D'água & 43 & 155 \\
\hline SC 302 (Sentido Calmon) & 40 & 144 \\
\hline Serra Azul & 38 & 116 \\
\hline Santana & 35 & 112 \\
\hline Adolfo Konder & 33 & 79 \\
\hline Cachoeirinha & 30 & 99 \\
\hline Taquara Verde (SC 451 Km 19 ao 25) & 29 & 107 \\
\hline Castelhano & 27 & 59 \\
\hline Benjamin Constant & 25 & 48 \\
\hline Casteli & 24 & 115 \\
\hline Seminário/Cachoeira & 24 & 96 \\
\hline Laranjeira & 24 & 60 \\
\hline Tamanduá & 22 & 80 \\
\hline Zanata & 20 & 65 \\
\hline Faxinal São Pedro & 20 & 46 \\
\hline São Judas Tadeu Sc 451 Km 17 & 18 & 39 \\
\hline São Sebastião SC 451 km 13 & 15 & 50 \\
\hline Turma 60 & 13 & 41 \\
\hline Colônia Japonesa & 11 & 41 \\
\hline Aliança & 10 & 128 \\
\hline Rio Tigre & 9 & 37 \\
\hline Aeroporto & 6 & 57 \\
\hline Chapada & 5 & 22 \\
\hline Paiol Velho & 5 & 10 \\
\hline SC 303 & 2 & 10 \\
\hline Presidente Pena & 1 & 3 \\
\hline
\end{tabular}




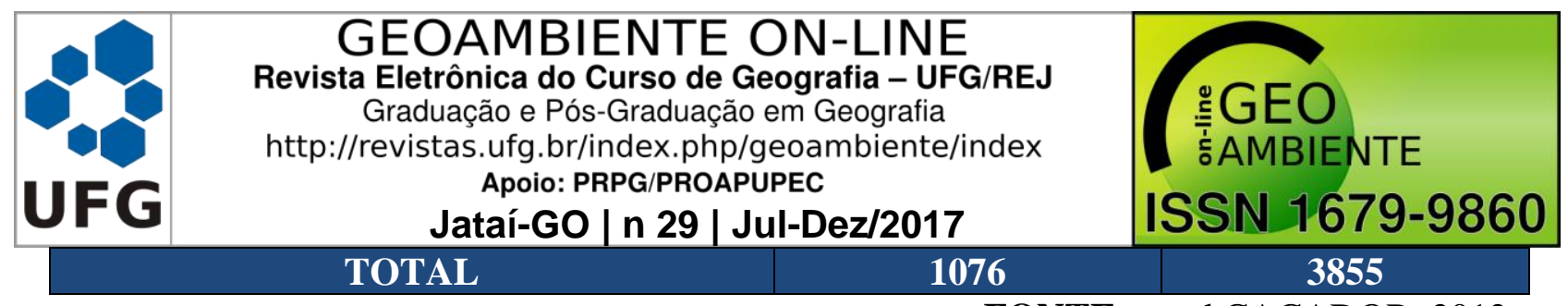

FONTE: apud CAÇADOR, 2012.

A Tabela 2. apresenta informações sobre o saneamento básico na área rural de Caçador, revelando a atual destinação do esgotamento sanitário no município, através de 1076 moradias entrevistadas, no entanto só 725 residências responderam o questionário.

Tabela2. Propriedades da área rural de Caçador com e sem tratamento de esgoto;

\begin{tabular}{|c|c|c|c|}
\hline \multirow{2}{*}{ Comunidade } & \multicolumn{3}{|c|}{ Número de Domicílio } \\
\hline & Poço Negro & Fossa/Filtro & Não Tem \\
\hline Assentamento & 90 & 19 & 3 \\
\hline Bugre & 73 & 28 & 5 \\
\hline Cará & 12 & 29 & 1 \\
\hline Serra Azul & 17 & 15 & 5 \\
\hline Adolfo Konder & 17 & 12 & 4 \\
\hline SC 451 & 20 & 38 & 8 \\
\hline S. Francisco & 16 & 27 & 6 \\
\hline Km 13 & 5 & 9 & 1 \\
\hline Casteli & 17 & 7 & 0 \\
\hline Cerro Branco & 32 & 35 & 1 \\
\hline Castelhano & 7 & 19 & 1 \\
\hline Cx D'água & 29 & 10 & 2 \\
\hline São Pedro & 25 & 19 & 1 \\
\hline B. Constant & 7 & 15 & 3 \\
\hline Paiol Velho & 0 & 5 & 0 \\
\hline C. Japonesa & 8 & 4 & 0 \\
\hline km 17 & 6 & 9 & 3 \\
\hline Aeroporto & 3 & 2 & 0 \\
\hline Taquara Verde & 9 & 15 & 3 \\
\hline Seminário/ Cachoeira & 10 & 13 & 1 \\
\hline Cachoeirinha & 11 & 18 & 1 \\
\hline Laranjeira & 8 & 13 & 3 \\
\hline Fx. São Pedro & 10 & 8 & 0 \\
\hline Turma 60 & 9 & 3 & 0 \\
\hline Rio Tigre & 1 & 7 & 1 \\
\hline Aliança & 6 & 1 & 0 \\
\hline Chapada & 2 & 3 & 0 \\
\hline Zanata & 12 & 7 & 0 \\
\hline Santana & 12 & 9 & 3 \\
\hline SC 302 & 20 & 19 & 1 \\
\hline SC 303 & 0 & 2 & 0 \\
\hline Tamanduá & 1 & 18 & 3 \\
\hline Presidente Pena & 1 & 0 & 0 \\
\hline TOTAL & 496 & 438 & 60 \\
\hline Desvio padrão & 19,07 & 9,80 & 2,03 \\
\hline Erro padrão & 3,32 & 1,71 & 0,35 \\
\hline$\%$ & 49.899 & 44.064 & 1.609 \\
\hline
\end{tabular}


Com base na Tabela 2. podemos observar que $49.899 \%$ (496) das propriedades possuem poço negro (sumidouro), 44.064\% (300) o sistema de fossa e filtro e apenas $1.609 \%$ (60) não possuem nenhum tipo de tratamento ou nem mesmo casa.O estudo foi realizado em 1076 residências da área rural, cobrindo 61,15\% (3855) da área rural do município de Caçador, sendo em área rural residem 6.304 habitantes. Segundo Freisleben, Grisa e Candiotto (2010) embora a maioria da população brasileira resida em zonas rurais, à falta de saneamento básico principalmente quando relacionado ao esgotamento sanitário é uma grande realidade, essa questão está associado sabre o atendimento prioritário nas aglomerações populacionais (cidades, sedes de distritos e outros).

Esse déficit no esgotamento sanitário da área rural do município de Caçador está relacionado com a inexistência do Plano Diretor Rural. O qual deveria fornecer parâmetros e métodos adequados para os sistemas que são implantados, resultando nas soluções semelhantes às urbanas, que utilizam como meio de disposição final adequadas para a disposição do esgotamento sanitário urbano. Silva, Morejon e Less (2014) descrevem que a falta de saneamento na área rural brasileira deixa as pessoas expostas a enfermidades provenientes da falta de tratamento de efluentes em área rural. Essas questões estão atreladas à falta de legislações, fiscalização e conhecimento das comunidades rurais.

Mesmo sendo essa a realidade brasileira é primordial a implantação de sistemas sustentáveis em áreas rurais, buscando a preservação dos recursos hídricos (FREISLEBN; GRISA; CANDIOTTO, 2010). Embora haja esforços pelas entidades governamentais para melhoria do esgotamento sanitário, muitos objetivos não são alcançados (SINGH, 2014). Para Leoneti, Prado e Oliveira (2011) é necessário um planejamento viável dos recursos a serem investidos para que seja desenvolvido um sistema integrado de qualidade para nosso país, não só apenas uma melhoria nos setores das organizações.

O órgão federal responsável pelas ações de saneamento é a Fundação Nacional de Saúde (FUNASA) o qual compete à implantação de ações de saneamento em áreas rurais de todos os municípios brasileiros conforme Plano Plurianual do Governo - PPA do saneamento em áreas rurais. O Ministério da Saúde - MS é responsável pela coordenação do Programa de Saneamento Rural, pela elaboração de um modelo conceitual em concordância com as especificidades dos territórios rurais, conforme as diretrizes do Programa Nacional de Saneamento Rural e do Plano Nacional de Saneamento Básico - PLANSAB. 


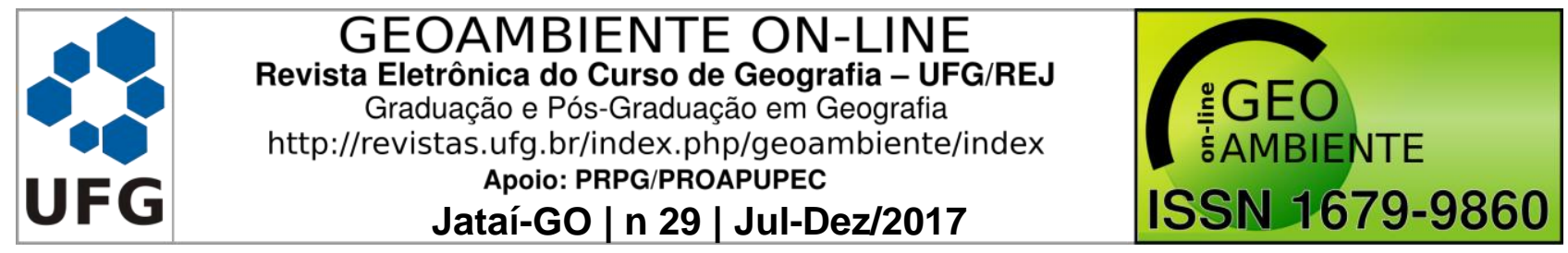

Em Santa Catarina as questões relativas ao saneamento estão afetas a Lei Estadual $\mathrm{n}^{\circ}$ 13.517 (2005), que dispõe sobre a Política Estadual de Saneamento e outras leis e decretos estaduais e federais. Um conjunto de regulamentos e normas administrativas com a finalidade de disciplinar o planejamento e a execução das ações, obras e serviços de saneamento no Estado, respeitando a autonomia dos Municípios. A legislação atribui à união, estados e municípios a responsabilidade de planejar, construir e manter os diversos sistemas de saneamento básico. O funcionamento destes serviços deve estar amparado em Planos de Saneamento Básico e respeitar as respectivas legislações. Porém é notório que as políticas públicas de saneamento ambiental estão com seus poucos esforços voltados para as áreas urbanas, deixando os moradores do interior a mercê da implantação de algumas ferramentas que são mais eficientes em não dispersar os poluentes em grande escala do que o tratamento e a reutilização dos mesmos.

A responsabilidade pela efetiva melhora no tratamento de efluentes sanitários rural é potencialmente aumentada pelo fato do município estar localizado nas margens do Rio do Peixe, importante rio que percorre parte do estado de Santa Catarina. O Rio do Peixe passa por 26 municípios, afetando diretamente mais de 250 mil habitantes que utilizam suas águas para indústria, agricultura, criação de animais e principalmente em suas residências. Por esse motivo tratar e destinar os efluentes gerados nas áreas rurais de Caçador é cuidar do Rio do Peixe e consequentemente a preservação da qualidade dos ecossistemas e dos moradores da região.

\section{Considerações Finais}

Através do estudo pode-se concluir que o saneamento básico com ênfase no esgotamento doméstico na área rural do município do estudo não possui um controle ambiental adequado, necessitando do aprimoramento da gestão publica e ambiental do município, onde para solucionar os problemas relacionados com o esgotamento sanitário na área rural do município é necessário desenvolver alternativa viável, sustentáveis e independentes para o tratamento do esgoto.

Ainda, observou-se à necessidade de melhorar o tratamento do esgoto rural, implantar o Plano Diretor Rural e apresentar aos moradores cartilhas de educação ambientais ou manuais técnicos de aplicação de sistemas alternativos e sustentáveis para o tratamento do esgoto gerado em residências rurais no município. Assim, o presente estudo mostra a necessidade da implantação de sistemas complementares ao processo de tratamento de esgoto 


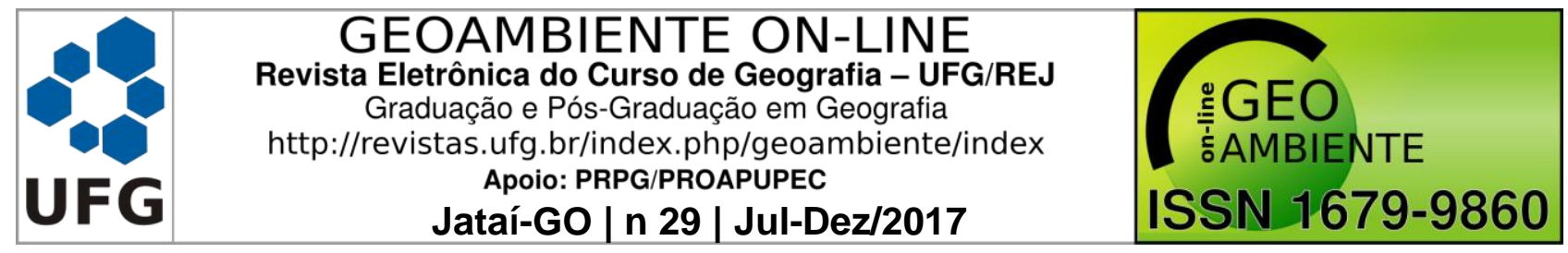

em área rural pelo município, obtendo o sistema de fitorremediação com perspectiva de solução para a diminuição desse impacto ambiental.

\section{Agradecimentos}

Agradeço á Secretaria Município de Agricultura de Caçador pela disponibilização dos dados, á Universidade Alto Vale do Rio do Peixe (UNIARP) pelo auxílio financeiro no desenvolvimento do trabalho e a empresa RT Engenharia e Consultoria Ambiental pela acessória perante o presente trabalho.

\section{Referências Bibliográficas}

BRAGA, B.; HESPANHOL, I.; CONEJO, J.G.L.; MIERZWA, J.C.; BARROS, M.T.L.; SPENCER, M.; PORTO, M.; NUCCI, N.; JULIANO, N.; EIGER, S. Introdução à engenharia ambiental: O desafio do desenvolvimento sustentável. 2. ed. São Paulo: Pearson Prentice Hall, 2005.

BRASIL. Instituto Brasileiro de Geografia e Estatística (IBGE). Pesquisa Nacional por Amostra de Domicílios - PNAD, 2012. Disponível em: http://www.ibge.gov.br/home/estatistica/populacao/trabalhoerendimento/pnad2012/default_si ntese.shtm. Acesso em: 19 set. 2015.

CALIJURI, M.C.; CUNHA, D.G.F. Engenharia ambiental: Conceitos, Tecnologia e Gestão. v.1. Rio de Janeiro: Elsevier. 2013.

CAÇADOR. Prefeitura Municipal. Secretaria Municipal de Agricultura. Levantamento das propriedades rurais do município de Caçador, 2012. Caçador: Secretaria de Agricultura, p.26, 2012.

COSTA, C.C.; GUILHOTO, J.M.G. Saneamento rural no Brasil: impacto da fossa séptica biodigestora. Revista Engenharia Sanitária e Ambiental, São Paulo. 2014. Disponível em: < http://www.scielo.br/pdf/esa/v19nspe/1413-4152-esa-19-spe-0051.pdf>. Acesso em: 28 jan. 2017.

FREISLEBEN, S.R.S.; GRISA, F.F.; CANDIOTTO, L.Z.P. Técnicas de saneamento básico e destino de efluentes em pequenas unidade rurais. In: Encontro Nacional de Geógrafos, 16. 2010. Rio Grande do Sul. Anais eletrônicos... Porto Alegre: AGB, 2010. Disponível em: <www.agb.org.br/evento/download.php?idTrabalho=1243>. Acesso em: 21 jan. 2017.

IBGE - Instituto Brasileiro de Geografia e Estatística. Pesquisa Nacional por Amostra de Domicílios

PNAD,

2012 .

Disponível

em: 
http://www.ibge.gov.br/home/estatistica/populacao/trabalhoerendimento/pnad2012/default_si ntese.shtm. Acesso em: 19 set. 2015.

IBGE - Instituto Brasileiro de Geografia e Estatística. Estatísticas. Contas Nacionais. Sistemas de Contas Nacionais - 2011. Disponível em: <http://www.ibge.gov.br/home/default.php>. Acesso em 15 fev. 2016.

IBGE - Instituto Brasileiro de Geografia e Estatística. Informações complementares - 2014. $<$ https://cidades.ibge.gov.br/xtras/perfil.php?lang=\&codmun=420300\&search=santacatarina|cacador|infograficos:-informacoes-completas>. Acesso em 15 fev. 2016.

LEONETI, A.B.; PRADO, E.L.; OLIVEIRA, S.V.W.B. Saneamento básico no Brasil: considerações sobre investimentos e sustentabilidade para o século XXI. Revista de Administração Publica - RAP, n .45, v.2, p.331-348, mar/abril, 2011.

LIMA, F.T.S.; PEREIRA, C.S.S.; PEREIRA, A.R.; CÂNDIDA, F.F.S. Projeto de Implantação de Sistema de Fossa Séptica Biodigestora e Clorador no Sítio Rio Manso/RJ. Revista Fluminense de Extensão Universitária, Vassouras, v.2, n.2, p.11-26, 2012.

NOVICKI, C.; CAMPOS, R.F.F. Análise da potabilidade das águas de fontes naturas, junto ao município de Fraiburgo/SC. Revista Monografias Ambientais - REMOA. v.15, n.1, p.323-336, 2016.

OTTERPOHL, R; BRAUN; U.; OLDENBURG, M. Innovative technologies for decentralised wastewater management in urban and peri-urban áreas. In: 5th Specialised Conference on Small Water and Wastewater Treatment Systems Istanbul-Turkey, p.27-36, 2002. PNAD - Pesquisa Nacional por Amostra de Domicílios - PNAD. Síntese de Indicadores 2012.<https://biblioteca.ibge.gov.br/visualizacao/livros/liv65857.pdf>. Acesso em 15 fev. 2016.

PNAD - Pesquisa Nacional por Amostra de Domicílios - PNAD. Síntese de Indicadores 2015.<https://biblioteca.ibge.gov.br/visualizacao/livros/liv98887.pdf>. Acesso em 15 fev. 2016.

RIZI JUNIOR, F. O saneamento básico na área rural e o papel das associações de moradores: O caso do Bairro Jardim Vitória. Revista Gestão em Foco, v,1, p.103-117. 2014.

SILVA, E.B.; ALVES, C.S.; PORTILHO, J.C.S. Diagnóstico Participativo de Saneamento Básico na comunidade rural do Baixo Rio Araguari, Município de Ferreira Gomes-Amapá, Brasil. Revista Biota Amazônia, Macapá, v.6, n.2, p.17-23, 2016. 


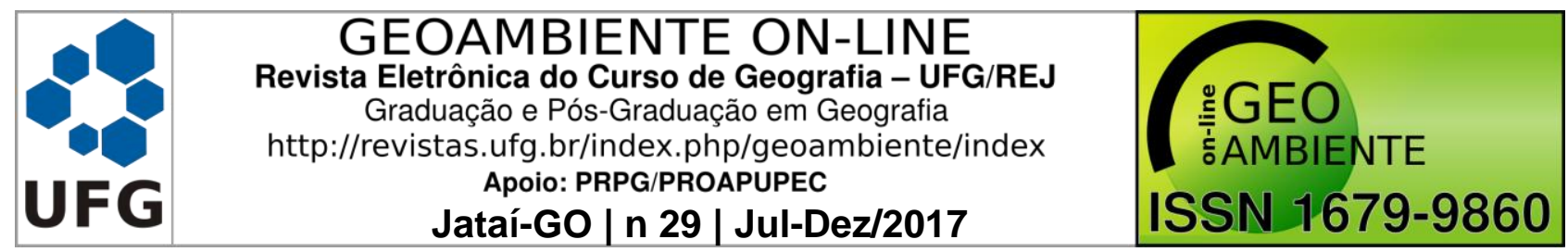

SILVA, D.F.; MOREJON, C.F.M.; LESS, F.R. Prospecção do panorama do saneamento rural e urbano no Brasil. Rev. Eletrônica Mestr. Educ. Ambient, v. especial, p.245-257, Mai. 2014.

SINGH, M.K. Sanitation in Rural India. Impact Journals, v.2, n.5, p.19-24, 2014.

UNICEF - The United Nations Children's Fund (2011). Estatística de saúde. Disponível em: http://www.unicef.org/sowc09/statistics/tables. php. Acesso em 10 Jan. 2016. 